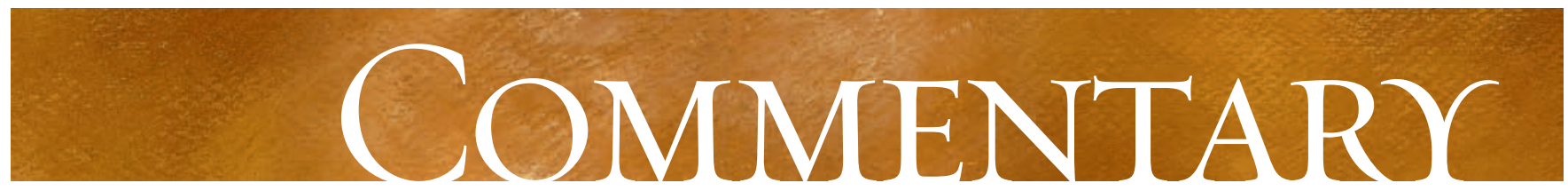

\title{
Injury in childhood: a vexingly simple problem
}

\section{Andrew W. Howard}

Published at www.cmaj.ca on Sept. 2I, 2006.

I $t$ is widely stated that $90 \%$ of childhood injuries are preventable. Why, then, are $\mathrm{I}$ in 8 hospital admissions of children the result of injury, and why are injuries still the leading cause of death among Canada's children?

Two articles in this issue of CMAJ help fill the gap between the evident simplicity and the surprising tenacity of the problem of childhood injury. Birken and associates examine the effect of socioeconomic status (SES) on trends in the rates of death from unintentional injury among Canadian children in urban areas (see page 867), ${ }^{1}$ and LeBlanc and collaborators study the relation between household safety measures and the risk of unintentional childhood injury (see page 883 ). ${ }^{2}$

Birken and associates investigated injury-related death rates among children living in urban centres in Canada between $197 \mathrm{I}$ and $\mathrm{I} 998$. They found an overall reduction of $8 \mathrm{I} \%$ in the risk of injury-related death among children over the study period. However, the risk increased as SES decreased from highest to lowest income quintile, particularly for deaths from falls, suffocations and pedestrian-motor vehicle collisions. This finding is consistent with those in the literature about injury (and many other health problems) and likely reflects multiple risk and protective factors at both the individual and community levels. (For injured children who were motor vehicle occupants or cyclists, the risk of death was similar across the SES quintiles, which may reflect higher exposure to driving and cycling among children of higher SES.) Of importance is the finding that the disparities in injury-related mortality attributable to SES did not widen over time in Canada, as they have in some countries, notably England and Wales. ${ }^{3}$ Because the determinants of injury are largely external to the health care system, this tells us that, in Canada, inequity based on SES is not getting worse. However, children of low SES still face a much higher risk of death from injury than do those of high SES, and we should strive to reduce this disparity rather than be satisfied that it is not widening.

LeBlanc and collaborators used a multicentre, prospective case-control design to investigate whether the number and type of hazards in the home varied between young children (4 years and less) seen at emergency departments with unintentional injuries and children matched by age and sex who presented to the emergency departments with non-injury-related conditions. Their study relied on home visits to identify hazards, an expensive but reliable measure of exposure. The authors found that the absolute number of hazards found in the case homes was higher than the number in the control homes, although the overall proportion of hazards did not differ statistically between the 2 groups. In the multivariable analysis, the authors found an association between injury and the presence of specific hazards in the home (baby walkers, choking hazards, no child-resistant lids on bathroom bottles, no smoke detectors and no functioning smoke detectors). The results regarding these specific hazards are credible because they come from a regression model in which the authors controlled for the presence of siblings, maternal education and parental employment, all of which were independently associated with injury in this study and in others. ${ }^{4}$ LeBlanc and collaborators conclude that the risk of injury among young children is associated with identifiable hazards in the home and that it extends beyond the specific hazards identified.

\section{As usual in injury control, we know more about what} has gone wrong and less

The few randomized trials of childproofing strategies in homes have been too small in scale to show statistically significant effects on injury outcomes. LeBlanc and collaborators conclude that the differences between the case and control homes with respect to several hazards "are too small to be incorporated into screening strategies..." but that "physicians should counsel for specific hazards supported by evidence of their effectiveness ... [and] advocate for the control of hazards that markedly increase the risk of serious injury, such as baby walkers."

Such advocacy is immediately relevant. In 2002 the Canadian Paediatric Surveillance Program surveyed more than IIoo pediatricians and found that $6.9 \%$ recalled treating I or more children younger than 18 months for injuries associated with baby walkers in the year before the survey. ${ }^{5}$ Although Canada banned the sale of baby walkers in 2004, the ban (still 
in effect) is currently under review. LeBlanc and collaborators found baby walkers in $21 \%$ of homes, and a 9-fold increase in the odds of injury associated with their presence. I hope, for the safety of our infants, that we will be guided by the evidence of the serious or fatal harm these devices predictably cause. Safekids Canada and the Canadian Paediatric Society are currently leading an advocacy campaign to uphold the ban, which has received broad support from physicians and the public.

Traffic-related injuries are responsible for the vast majority of injury-related deaths and long-term disabilities of Canadian children. In addition, injuries occurring in the home and those from sports and leisure activities are responsible for the bulk of younger and older children, respectively, being taken to emergency departments and admitted to hospital. Each of these injury mechanisms can be addressed by clinicians in multiple ways. Counselling parents regarding the optimal use of child restraints in vehicles addresses the most important modifiable risk factor for most children. ${ }^{6}$ The promotion of safe walking and cycling at the individual or community level addresses both injury risk and the long-term health risks of sedentary living. ${ }^{7}$ Physician counselling and environmental modification make the home environment safer for young children. ${ }^{8,9}$ Modifications to play equipment and to rules of play can make sports and leisure activities safer. ${ }^{10,11}$ Other legislative initiatives, such as those controlling the appropriate use of booster seats and bicycle helmets - laws that save lives ${ }^{12}$ - depend heavily on advocacy from physicians and the public.

As usual in injury control, however, we know more (but not enough) about what has gone wrong and less about how exactly to make it right. This gap makes the simple problem of injury prevention complex. Birken and associates have shown us that, although injury-related mortality has decreased over time, it remains unacceptably high and children of low SES are still at increased risk. This helps us to target interventions. LeBlanc and collaborators provide good evidence of an association between hazards in the home and injury risk among young children. The association is neither strong enough nor straightforward enough to translate into an immediate intervention. As with the randomized trials that supported the relation between reduction in home hazards and reduction in injuries (but were too small to document injury outcomes ${ }^{8,9}$ ), LeBlanc's study does support physician counselling and childproofing strategies to reduce the risk of injury at home among children under 5 years old. Designing, testing and implementing injury control interventions remain the challenges for the medical community, and injury remains a vexingly simple leading cause of death to defeat. Given the importance of SES in injury risk, as with many other public health issues, decreasing injury-related mortality will require a societal approach, not simply a medical approach.

\section{This article has been peer reviewed.}

Andrew Howard is with the Department of Orthopedics, The Hospital for Sick Children, Toronto, Ont.

Competing interests: None declared.

\section{REFERENCES}

I. Birken CS, Parkin PC, To T, et al. Trends in rates of death from unintentional injury among Canadian children in urban areas: influence of socioeconomic status. CMAJ 2006; $175(8): 867-8$.

2. LeBlanc JC, Pless IB, King WJ, et al. Home safety measures and the risk of unintentional injury among young children: a multicentre case-control study. CMAJ 2006;175(8):883-7

3. Roberts I, Power C. Does the decline in child injury mortality vary by social class? A comparison of class specific mortality in I98I and I99I. BMJ I996;313:784-6.

4. Nathens $\mathrm{AB}$, Neff MJ, Goss $\mathrm{CH}$, et al. Effect of an older sibling and birth interval on the risk of childhood injury. Inj Prev 2000;6:219-22.

5. Baby walker survey: results and next steps. Paediatr Child Health 2002;7:418.

6. Howard AW. Automobile restraints for children: a review for clinicians [review]. CMAJ 2002; $167(7): 769-73$.

7. Durkin MS, Laraque D, Lubman I, et al. Epidemiology and prevention of traffic injuries to urban children and adolescents. Pediatrics I999;I03:e74

8. Clamp M, Kendrick D. A randomised controlled trial of general practitioner safety advice for families with children under 5 years. BMJ I998;316:1576-9.

9. Kendrick D, Marsh P, Fielding K, et al. Preventing injuries in children: cluster randomised controlled trial in primary care. BMJ I999;318:980-3.

Io. Howard AW, MacArthur C, Willan A, et al. The effect of safer play equipment on playground injury rates among school children. CMAJ 2005;I72(II):I443-6.

II. Macpherson A, Rothman L, Howard A. Body-checking rules and childhood injuries in ice hockey. Pediatrics 2006; II7:er43-7.

I2. Macpherson AK, To TM, Macarthur C, et al. Impact of mandatory helmet legislation on bicycle-related head injuries in children: a population-based study. Pediatrics 2002;110:e6o.

Correspondence to: Dr. Andrew W. Howard, The Hospital for Sick Children, Department of Orthopedics, Rm. SIO7, 555 University

Ave., Toronto ON M5G IX8; fax $4 I_{6} 6 \mathrm{II}_{3}-64 \mathrm{I} 4$;

andrew.howard@sickkids.ca

\section{Holiday Review 2006 Call for submissions}

Hilarity and good humour ... help enormously in both the study and the practice of medicine ... [I]t is an unpardonable sin to go about among patients with a long face.

$$
\text { — William Osler }
$$

Yes, that's right, it's time to send us your creative contributions for CMAJ's Holiday Review 2006. We're looking for humour, spoofs, personal reflections, history of medicine, off-beat scientific explorations and postcards from the edge of medicine.

Send your offerings through our online manuscript tracking system (http://mc.manuscriptcentral.com/cmaj). Articles should be no more than 1200 words; photographs and illustrations are welcome. Please mention in your cover letter that your submission is intended for this year's Holiday Review.

The deadline for submissions is Oct. 16, 2006. 